\title{
Brinquedoteca hospitalar: 0 lúdico como instrumento de mediação na recuperação de crianças enfermas
}

Maria Aparecida Valentim de Souza Leite ${ }^{1}$, Naíse Valéria Guimarães Neves ${ }^{2}$, Maria de Lourdes Mattos Barreto ${ }^{3}$, Rita Sant'Anna e Castro ${ }^{4}$, Cristiana Terezinha de Jesus ${ }^{5}$, Roseli Silva ${ }^{6}$, Bethania de Assis Costa ${ }^{7}$

RESUMO: Este artigo refere-se ao Projeto de Extensão intitulado "Brinquedoteca Hospitalar: Uma Estratégia de Humanização às Familias e Crianças Atendidas no Hospital São Sebastião em Viçosa, Minas Gerais". O projeto visa implementar o trabalho de humanização proposto pelo Hospital São Sebastião no que se refere ao atendimento às crianças internadas e suas famílias por meio de atividades lúdicas, proporcionando condições favoráveis para que elas possam conviver bem com os diferentes sentimentos gerados no ambiente hospitalar.

Palavras chave: Brinquedoteca hospitalar, criança, saúde.

Áreas Temáticas: Educação e saúde.

\footnotetext{
1 Graduanda do curso de Educação Infantil da Universidade Federal de Viçosa, MG; bolsista PIBEX 2012 maria.leite@ufv.br.

2 Economista Doméstico. M. S. Em Economia Doméstica; Orientadora e Coordenadora do Projeto Professora DED/UFV. nneves@ufv.br

3 Prof ${ }^{a}$ Associada do Departamento de Economia Doméstica da Universidade Federal de Viçosa UFV/DED/MG. mmattos@ufv.br

${ }^{4}$ Economista Doméstico, coordenadora da Brinquedoteca do Hospital São Sebastião em Viçosa, MG. rmsannac@hotmail.com

${ }^{5}$ Graduanda do curso de Economia Doméstica da Universidade Federal de Viçosa, MG; membro da equipe do projeto PIBEX.cristiana.lucas@ufv.br

6 Graduanda do curso de Educação Infantil da Universidade Federal de Viçosa, MG; membro da equipe do projeto PIBEX roseli.silva@ufv.br

7 Educadora Infantil. M.S. em Economia Doméstica na Universidade Federal de Viçosa, MG; Colaborador. bethania.assisc@ufv.br
} 


\section{Hospital Brinquedoteca: The playful mediation as a tool in the recovery of sick children}

ABSTRACT: This article refers to the Extension Project entitled "Hospital Brinquedoteca: a Strategy to Humanize Families and Children Cared at the Hospital São Sebastião in Viçosa, Minas Gerais". This project aims to implement humanization work as proposed by the Hospital São Sebastião in relation to care for hospitalized children and their families through recreational activities providing favorable conditions so that they can get along with different feelings caused by the hospital.

Keywords: Children, health, hospital playroom.

Thematic areas: Education and health.

\section{Brinquedoteca del hospital: La mediacion lúdica como her- ramienta para la recuperacion de lãs niños enfermos}

RESUMEN: Este artículo se refiere al proyecto de extensión titulado "Brinquedoteca del hospital: una estrategia para humanizar a las familias y los niños atendidos en el Hospital São Sebastião en Viçosa, Minas Gerais", dirigido a la aplicación de la humanización del trabajo propuesto por el Hospital São Sebastião en relación con atención a los niños hospitalizados y sus familias a través de actividades recreativas que proporcionan condiciones favorables para que puedan llevarse bien con los diferentes sentimientos que se generan en el entorno hospitalario.

Palabras clave: Brinquedoteca, Niños, Salud.

Áreas temáticas: Educación y salud. 


\section{INTRODUÇÃO}

Brincar faz parte da vida humana. É por meio do brincar que as crianças têm contato, compreendem e aprendem a lidar com o mundo em que vivem. Além disso, brincar é prazeroso e satisfatório, é uma atividade livre e espontânea que inclui ações com uma linguagem própria em cada brinquedo, podendo ser este a própria palavra, a música, a história, o movimento, o desenho, o objeto. Brincando, as crianças constroem seu próprio mundo e os brinquedos são ferramentas que contribuem para essa construção. É com os brinquedos que elas começam a desenvolver sua habilidade e criatividade para mudar o mundo. Quando as crianças têm oportunidades para brincar, dispõem de brinquedos para brincar, individualmente ou em grupos, vivem uma experiência que enriquece sua sociabilidade e sua capacidade de se tornar seres humanos criativos. Os brinquedos fazem com que as crianças compreendam que o mundo está cheio de possibilidades. Os brinquedos desempenham um papel decisivo para tornar as crianças de hoje adultos maduros com grande capacidade de imaginação e autoconfiança.

De acordo com Maia (2000), o brincar possibilita à criança construir e elaborar a relação eu - mundo, pois além do prazer proporcionado através do brincar, ela domina suas angústias, controla ideias ou impulsos. É inquestionável seu papel no crescimento gradual da criança, que encontrará no brincar as experiências cotidianas equivalentes às do adulto. Neste sentido sabemos que a hospitalização da criança interrompe este processo, promovendo uma ruptura em suas experiências, pois o ambiente hospitalar não representa as condições essenciais para atender tal necessidade infantil. Os trabalhos desenvolvidos em brinquedotecas hospitalares normalmente são de caráter clínico-preventivo, tendo como objetivo o atendimento à criança hospitalizada, através da utilização terapêutica de atividades lúdicas.

As brinquedotecas hospitalares buscam amenizar o trauma psicológico da internação e minimizar suas presumíveis sequelas, além de atenuar o sofrimento infantil, contribuindo com a recuperação e consequentemente com a redução do tempo de internação. Esse tipo de brinquedoteca pode atender tanto aos pacientes infantis internados no setor de pediatria de um hospital geral, quanto à sua família e à equipe hospitalar, proporcionando condições de reflexão e instrumentalização, contemplando as necessidades básicas da criança hospitalizada.

O projeto "Brinquedoteca Hospitalar: Uma estratégia de Humanização às Crianças e Famílias Atendidas no Hospital São Sebastião de Viçosa, Minas Gerais" visa implementar o trabalho de huma- 
nização proposto pelo Hospital São Sebastião no que se refere ao atendimento às crianças internadas e suas famílias por meio de atividades lúdicas proporcionando condições favoráveis para que elas possam conviver bem com os diferentes sentimentos gerados no ambiente hospitalar.

O projeto da brinquedoteca nasceu no Laboratório de Desenvolvimento Humano do Departamento de Economia Doméstica da Universidade Federal de Viçosa, sendo um jeito simples de ajudar na recuperação de crianças que precisam ficar algum tempo no hospital para tratamento. Ter ali um espaço para brincar às vezes é tão importante quanto os remédios e os cuidados médicos (GUIMARÂES \& MOL, 2005).

Criada em 1993, a Brinquedoteca do Hospital São Sebastião (HSS), em Viçosa, Minas Gerais, foi implantada por uma Economista Doméstico, 12 anos antes da promulgação da Lei no 11.104, aprovada em 21 de março de 2005, que obriga os hospitais que possuem unidades pediátricas a ter um espaço para brincadeiras e jogos educativos. A brinquedoteca esteve desativada por alguns anos, voltando a funcionar em 2006, por meio do projeto de extensão da Universidade Federal de Viçosa intitulado "Brinquedoteca Hospitalar: Uma estratégia de Humanização às Crianças e Famílias Atendidas no Hospital São Sebastião de Viçosa, Minas Gerais". Assim, em parceria com o Departamento de Economia Doméstica e o Curso de Educação Infantil da UFV, o HSS - Viçosa/MG objetiva oportunizar um atendimento humanizado, por meio de realização de atividades lúdicas com as crianças, a toda a comunidade que necessite da utilização desse serviço.

O presente trabalho busca apresentar as experiências vivenciadas e os benefícios deste projeto de extensão proporcionados às crianças hospitalizadas e suas famílias que residem em Viçosa e microrregião. O projeto tem como objetivo geral desenvolver atividades lúdicas junto às crianças internadas no Hospital São Sebastião, no espaço da brinquedoteca e nos leitos/pediatria, visando auxiliar na recuperação da criança por meio da redução do sofrimento causado pelo processo de internação e adoecimento, e assim promovendo a humanização hospitalar.

\section{A importância do brincar para o desenvolvimento da criança dentro da brinquedoteca hospitalar}

De acordo com Miller (2008), cada vez que uma criança é hospitalizada, é um momento de estresse para a família. A criança sem dúvida ficará ansiosa e poderá enfrentar medos reais. A ansiedade dos pais com o bem-estar de seus filhos e com possíveis dificulda- 
des financeiras também afetará a criança hospitalizada e as outras crianças da família (se houver), as mesmas sentirão falta dos pais e terão suas preocupações. A maneira como os pais lidam com a doença do filho tem um grande impacto no modo como a criança aprende a lidar com a experiência. A autora também afirma que as crianças sentem-se vulneráveis e impotentes no hospital, onde elas estão em uma situação em que não têm controle ou poder.

Dentre as dificuldades enfrentadas pela criança no ambiente hospitalar, ela pode acreditar que o fato de estar doente está relacionado a alguma atitude má (MILLER, 1998). Para a autora, mesmo que ela não expresse isso, deve-se deixar claro que ela não está doente por causa de alguma coisa que tenha feito. As consequencias emocionais da hospitalização podem interferir no desenvolvimento infantil. Para Angerami-Camon (1987), há várias interrupções na vida cotidiana da pessoa hospitalizada como, por exemplo, alterações no ritmo da vida familiar, carências afetivas, agressões físicas e psicológicas, dentre outras. Na hospitalização, segundo este autor, há uma quebra da situação de domínio sobre si, pois neste momento a pessoa passa de um estado ativo para um estado passivo ou "paciente", em ambos os sentidos, orgânico e psicológico.

Sob outro ponto de vista, Mitre e Gomes (2003) discorrem sobre a despersonalização do paciente. A princípio, neste novo local que é o hospital, a pessoa tem a sensação que seu nome, seus gostos, seus objetos pessoais não têm importância. Neste sentido, estes autores vêm dizendo que o sujeito neste momento está sendo destituído de seus papéis sociais e torna-se mais um caso. O paciente se sente despido de sua própria pessoa, deixando sua identidade em casa e passando a ser uma patologia a mais. Este primeiro momento é difícil e desperta sentimentos como angústia, medo, insegurança, saudade dos amigos e familiares. Diante do exposto, considera-se que o brincar dentro do hospital é um recurso que auxilia em muitos aspectos como, por exemplo, na aceitação do tratamento, integralidade da atenção, além de ser um elo de comunicação entre criança-enfermeiros-acompanhantes, ou seja, entre toda a equipe envolvida no proceso. Quando esta oportunidade é oferecida às crianças, pode ser vista de uma forma mais amenizada (MILTRE \& GOMES, 2003).

A assistência à saúde tem a inclusão de um processo de interação social complexo entre os indivíduos que atuam no setor tanto hierarquicamente quanto funcionalmente. Ao relacionar-se consigo mesmo, com o outro e com um todo é preciso levar em conta elementos como a saúde e a doença. As condições de saúde e doença são 
demonstradas através de fatores biológicos, avaliados pelos estudos de medicina e genética, modo de vida, comportamentos de um indivíduo. Quando uma pessoa se encontra adoentada, ela se encontra em uma situação desfavorável ao pleno desenvolvimento, sendo necessário o planejamento de oportunidades compensatórias que minimizem o possível impacto no desenvolvimento humano (DESSEN \& COSTA JUNIOR, 2005). Segundo Chiattone (2003), o atendimento técnico, impessoal, com tom de voz agressivo deve ser evitado no tratamento com criança doente, pois os profissionais da saúde muitas vezes incluem no conceito de saúde apenas o bem estar físico do doente, menosprezando outros aspectos afetivos e psicossociais.

A criança hospitalizada de acordo com Soares (2003) sofre com fatores estressores: enfermidade, dor, ambiente não familiar, pessoas estranhas, sons de aparelhos (bips, alarmes, outros), instrumentos "apavorantes", odores quase sempre desconhecidos que, aliados ao fato de sentir dores e ser submetida a procedimentos invasivos, levam-na ao medo, insegurança e muitas vezes, a apresentar atitudes agressivas e/ou comportamentos regressivos.

A partir das reflexões sobre o brincar apresentadas por parte de estudantes do curso de Educação Infantil, enfermeiras, crianças hospitalizadas e suas famílias, podemos entender que a promoção do mesmo pode, consciente ou inconscientemente, ser essencial para minimizar o processo de distanciamento que geralmente ocorre entre criança e o profissional de saúde. Neste sentido, os estudos de autores como Vygotski (1984), Smole (2003) e Brougère (1997) contribuem para a reflexão sobre as relações estabelecidas entre as crianças e os profissionais de saúde que trabalham no hospital São Sebastião, uma vez que versam sobre a importância do brincar na vida humana. $\mathrm{O}$ ato de brincar oferece à criança a oportunidade de viver sua infância descobrindo, explorando, aprendendo, resolvendo, persistindo, convivendo e se comunicando com o mundo de forma espontânea, criativa, autônoma e feliz. Portanto, a promoção do brincar no espaço hospitalar refletirá positivamente na vida da criança, neste momento específico em que ela se encontra em tratamento médico, permitindo-a expressar seus sentimentos e necessidades que podem estar fragilizados e ampliados.

O pensar sob esta perspectiva nos mostra a necessidade de promover ações lúdicas na busca de novos significados para o atendimento à criança hospitalizada, que deve ser vista como ser integral que possui uma subjetividade e histórias de vida diferentes. Portanto, ressalta-se a importância da atuação de uma equipe multidisciplinar num espaço chamado brinquedoteca, onde o brincar assume um papel importante na promoção da pessoa humana. Vygotski 
(1984) afirma que brincando a criança aprende a linguagem dos símbolos e entra no espaço original de todas as atividades socio-criativo-culturais.

O brincar é um indicativo revelador de culturas, sua análise permitirá ou não que os traços culturais da sociedade em questão sejam evidenciados. Sendo a criança sujeito cultural, o seu brinquedo tem as marcas do real e do imaginário vividos por ela, neste sentido "a brincadeira pode ser considerada uma forma de interpretação dos significados contidos nos brinquedos" (BROUGÈRE, 1997).

Smole (2003) concorda com os demais autores ao afirmar que, ao brincar, a criança pensa, reflete e organiza-se internamente para tentar compreender a situação que ela está vivendo. A autora ainda menciona que, quando a criança brinca, é colocada diante de desafios e problemas, devendo constantemente buscar soluções para as situações a ela colocadas. Portanto, brincar também é uma forma de resolver problemas; neste sentido, é fundamental observar a manifestação corporal da criança e tentar "ler" o que ela está expressando com seus gestos.

Cunha (2005) aponta que o brincar é fundamental para a criança expressar suas necessidades e desenvolver suas potencialidades. $\mathrm{O}$ desafio contido nas situações lúdicas provoca o pensamento, exercita habilidades, levando a criança a se sentir mais confortável para enfrentar suas inseguranças. Diante disso, ressalta-se a necessidade e a importância de um espaço para vivências lúdicas, como a brinquedoteca, em um ambiente hospitalar. Brinquedoteca é

um espaço preparado para estimular a criança a brincar, possibilitando o acesso a uma grande variedade de brinquedos, dentro de um ambiente especialmente lúdico. E um lugar onde tudo convida a explorar, a sentir, a experimentar (CUNHA, 1992, p.35).

Ao pensarmos a brinquedoteca hospitalar sob uma perspectiva piagetiana, podemos afirmar que ela é de grande importância para o desenvolvimento da criança, pois é um ambiente que proporciona trocas e intercâmbios entre as crianças e delas com os objetos ali presentes. Essas interações acontecem num espaço onde predomina um mundo com características do universo infantil e que busca dar novo olhar à atenção de saúde da criança enferma que vivencia a internação hospitalar (CECCIM, 1997).

De acordo com Santa Rosa (2001), onde existem crianças, existem brinquedos e brincadeiras, existem crianças que adoram brincar, inventar e criar, pois assim elas entendem melhor o mundo dos 
adultos. Crianças de todo o mundo brincam e sempre brincaram. Seja utilizando objetos ou não, competindo ou ajudando seu companheiro, as crianças se divertem, desenvolvem e constroem seu pensamento e sua lógica.

Para Kishimoto (1992), brincar é um direito de qualquer criança, inclusive daquela que se encontra hospitalizada. Nessa situação, além da doença, a criança sofre com a imobilização, que a priva do seu comportamento mais típico, o brincar. A utilização do jogo como instrumento terapêutico baseia-se na ideia de que, ao brincar, a criança se recupera e se expressa mais rapidamente.

Com frequência, para aceitar, compreender e ultrapassar o problema vivido pela internação, a criança brinca de "ser médico". Onde os "doentes" são as bonecas, os ursos, os companheiros de quarto. Com roupas, máscaras, estetoscópios, aparelhos de medir pressão, seringas e bandagens, a criança brinca e representa a sua própria condição de criança hospitalizada. Por meio de tais brincadeiras ela encontra mecanismos para enfrentar seus medos e angústias. Estimular tais brincadeiras é auxiliá-las na sua recuperação. (KISHIMOTO, 1992, p.55).

Para Paula e Foltran (2008), a brinquedoteca hospitalar é o espaço onde os pacientes vivem situações onde podem compartilhar brinquedos, histórias, emoções, alegrias e temores da condição em que se encontram. Neste espaço, há uma maior aproximação de todas as pessoas envolvidas no processo, particularmente pais e filhos, onde é permitido à criança usufruir o brincar, direito garantido por lei.

Um grande avanço conquistado no nosso país é o reconhecimento legal da importância de brinquedotecas em hospitais que possuem o setor pediátrico. Neste sentido, do ponto de vista legal, a Lei $\mathrm{n}^{\circ} 11.104$, aprovada em 21 de março de 2005, obriga os hospitais que possuem unidades pediátricas a instalar brinquedotecas, exemplificada nos artigos $1^{\circ}$ e $2^{\circ}$ :

Art. $1^{\circ}$ : Os hospitais que ofereçam atendimento pediátrico contarão com brinquedotecas nas suas dependências.

Parágrafo único: O disposto no caput deste artigo aplica-se a qualquer unidade de saúde que ofereça atendimento pediátrico em regime de internação. 
Art. $2^{\circ}$ : Considera-se brinquedoteca, para os efeitos desta Lei, o espaço provido de brinquedos e jogos educativos, destinado a estimular as crianças e seus acompanhantes a brincar.

De acordo com as concepções do brincar, uma brinquedoteca pode ter vários objetivos, entre os quais se destacam: estimular o desenvolvimento integral das crianças; valorizar o brincar e as atividades lúdicas; estimular a criatividade, desenvolver a imaginação, a comunicação e a expressão; possibilitar à criança o acesso a vários tipos de brinquedos e de brincadeiras; incentivar a brincadeira do faz-de-conta, a dramatização, a construção, a solução de problemas, a socialização; enriquecer as relações familiares através da participação dos adultos nas atividades infantis; emprestar brinquedos e desenvolver hábitos de responsabilidade e cooperação entre as crianças e entre crianças e adultos. Existem, no Brasil e no mundo inteiro, brinquedotecas que funcionam para atingir um ou vários destes objetivos ou ainda com preocupações específicas, dependendo do contexto onde foram criadas.

De acordo com Armond (2002), a proposta de uma brinquedoteca hospitalar deve ser compreendida em uma dimensão mais ampla do que simplesmente divertir as crianças. A criança que se encontra internada não deixa de ser criança. Por isso, além dos especiais cuidados para a recuperação de sua doença, ela necessita receber condições favoráveis ao seu desenvolvimento e aprendizagem. Neste caso, as brincadeiras, os jogos, as histórias irão exercer um papel tão importante quanto os medicamentos que lhes serão administrados.

Ao reconhecer a criança como ser total, verifica-se que existem outras necessidades na vida infantil que são primordiais ao seu desenvolvimento, e não apenas necessidades clínicas, que naquele momento da vida são sim relevantes; no entanto, há outros aspectos que possuem igual relevância no agravamento ou restabelecimento da doença.

\section{METODOLOGIA}

O presente trabalho é desenvolvido no Hospital São Sebastião, com as crianças internadas na pediatria e em quartos particulares. A Casa de Caridade de Viçosa, Hospital São Sebastião, é uma instituição filantrópica e situa-se na Rua Tenente Kümmel, Viçosa-MG. Em 31 de dezembro de 2011 havia em seu quadro funcional 317 servidores, o corpo clínico composto de 103 médicos e 1 cirurgião dentista (Relatório HSS, 2011). O Hospital São Sebastião conta com uma brinquedoteca que funciona desde 1993, oferecendo às 
crianças internadas no setor da pediatria, um programa de atividades lúdicas, planejadas especificamente para atendê-las.

A brinquedoteca proporciona um ambiente planejado e organizado compreendendo uma área interna e uma área externa, reformadas recentemente (com recursos angariados por meio desse projeto de extensão), a fim de atender as crianças de diferentes idades e limitações decorrentes da internação. Essas áreas foram adaptadas e equipadas com mobiliários, equipamentos e brinquedos que buscam amenizar os efeitos da internação hospitalar, tanto no aspecto físico quanto no aspecto psicológico.

Ao oferecer oportunidades recreativas, acredita-se que esta área de lazer também poderá despertar nos pais uma consciência mais profunda das necessidades de seus filhos, uma vez que estão vivenciando uma situação tão adversa como esta de internação e doença. Em 2012, o projeto completou 6 anos de ação extensionista junto ao referido Hospital pelo objetivo de dar continuidade às ações desenvolvidas no espaço da brinquedoteca e nos leitos pediátricos, proporcionando atividades lúdicas às crianças na faixa etária de 0 a 14 anos de idade que se encontram em regime de internação e aos seus familiares ou respectivos acompanhantes, promovendo a humanização hospitalar.

As atividades desenvolvidas com as crianças são planejadas de acordo com alguns critérios: quadro clínico da criança, idade, interesse pelos brinquedos e materiais e o número de crianças internadas. Antes de desenvolver as atividades, as estagiárias ou voluntárias conversam com os acompanhantes das crianças e preenchem uma ficha com os dados de cada criança. Por meio desta ficha, são coletadas informações sobre: enfermidade da criança; idade; as condições físicas para que a criança caminhe até a brinquedoteca; reincidência no hospital, dentre outras questões importantes para o desenvolvimento das atividades. Além disso, é por meio desta ficha que é feito o primeiro contato com a criança e seus familiares, momento em que é falado sobre a brinquedoteca do HSS, o trabalho nela desenvolvido e sua importância.

As crianças que podem se locomover são convidadas a ir à brinquedoteca, localizada à parte da unidade pediátrica. Sempre incentivamos o acompanhamento dos familiares da criança até a brinquedoteca, já que objetivamos promover a interação entre criança e família durante as atividades lúdicas. As crianças que, pela enfermidade, necessitam ficar em repouso, recebem brinquedos e materiais lúdicos nos próprios leitos. As atividades nos leitos são realizadas incentivando a participação dos pais ou dos acompanhantes, e buscam atender a preferência da criança, podendo ser qualquer ativi- 
dade como as desenvolvidas no espaço da brinquedoteca, desde que não comprometa o tratamento da criança.

Durante as atividades lúdicas e entrevista aos acompanhantes, sempre procuramos estar atentos aos horários cujos médicos, enfermeiros, nutricionistas e outros profissionais estão realizando o atendimento às crianças. Da mesma forma, os horários das refeições, que sempre são respeitados pela equipe do projeto, não permitindo o desenvolvimento das atividades lúdicas no espaço da brinquedoteca no horário em que as refeições são administradas.

O espaço interno da brinquedoteca é dividido em cantos ou áreas de interesse, assim denominados: "No mundo da fantasia"; "Jogar, criar e inventar"; "Pintar, bordar e rabiscar"; "Faz de conta que sou!" e "Brinquedos de Quintal".

No mundo da fantasia são desenvolvidas atividades relacionadas à leitura e contação de histórias. Nesta área, as crianças podem escolher se querem que as estagiárias ou a bolsista do projeto conte uma história ou se ela mesma quer ler. Além de livros, são utilizados recursos como fantoches e flanelógrafo. Por meio destas histórias é possível conhecer mais sobre a vida de muitas crianças, que nos contam fatos e acontecimentos vivenciados por elas, parecidos com a história contada. A história também permite o desenvolvimento de outras brincadeiras, pois muitas vezes as crianças representam a história que ouviram por meio de bonecos e outros brinquedos.

No canto "Jogar, criar e inventar", a criança tem a possibilidade de criar e inventar suas próprias regras ou seguir as que estão sugeridas nas variadas opções de jogos, como por exemplo, quebra-cabeça, dominó, jogo da memória, trilha e diversos outros brinquedos manipulativos, com os quais as crianças podem brincar sozinhas, com outras crianças, com seus acompanhantes ou com as voluntárias. Este tipo de brinquedo é muito utilizado pelas crianças que necessitam ficar em repouso como, por exemplo, aquelas crianças que passaram por procedimentos cirúrgicos ou tem problemas cardíacos, pois estes tipos de atividades não exigem muitos movimentos.

No "Pintar, bordar e rabiscar" há materiais disponibilizados como lápis de cor, giz de cera, caneta hidrocor, tintas, cola, tesoura, papel A4, cartolina, papel camurça, entre outros, para que a criança tenha liberdade para se expressar e possibilidade de exploração dos mais variados materiais. A importância destas atividades se dá na medida em que é possível identificar espontaneidade e autonomia na exploração e no fazer artístico das crianças. Seus trabalhos revelam o local e a época histórica em que vivem; suas oportunidades de aprendizagem; seus medos; expectativas de futuro; conhecimentos; 
habilidades; suas idéias ou representações sobre o trabalho artístico que realiza e sobre a produção de arte à qual têm acesso, assim como seu potencial para refletir sobre ela.

As crianças têm suas próprias impressões, idéias e interpretações sobre a produção de arte e o fazer artístico. Tais construções são elaboradas a partir de suas experiências ao longo da vida, que envolvem a relação com a produção de arte, com o mundo dos objetos e com seu próprio fazer. As crianças exploram, sentem, agem, refletem e elaboram sentidos de suas experiências. A partir daí constroem significações sobre como se faz, o que é, para que serve e sobre outros conhecimentos a respeito da arte.

O canto denominado "Faz de conta que sou!" possui três miniaturas de berços e de suporte de soro, onde ficam bonecas que representam o espaço da pediatria hospitalar. A representação é realizada de diversas maneiras usando bonecas, carrinhos, animais de borracha, acessórios (óculos, bolsas, fantasias), telefones, e outros. Neste ambiente há brinquedos que podem ajudar na aceitação do quadro clínico como, por exemplo, seringas, estetoscópio, roupas de médico e enfermeiro entre outros materiais. Por meio da brincadeira de faz-de-conta, a criança pode representar a experiência vivenciada no hospital, brincando de médico (a) com outras crianças e bonecas, e manipulando materiais usados pelos profissionais da saúde.

Para brincar com "brinquedos de quintal" utilizamos o gramado do espaço externo onde são propostas atividades com bolas, velocípedes, bambolês, cavalo-de-pau, petecas, carrinhos, dentre outros. Esse tipo de atividade é indispensável à vida da criança e, dependendo da natureza da doença ela tem oportunidade de exercitar-se fisicamente.

\section{RESULTADOS}

As crianças e familiares, bem como os demais acompanhantes, foram receptivos à proposta do brincar neste espaço de hospitalização. No período compreendido aos meses de fevereiro a 15 de novembro do ano de 2012, foram atendidas 302 crianças e seus respectivos acompanhantes (mãe, pai, avó, tia etc). Destas, podemos inferir que $17,2 \%$ foram reincidentes no hospital, sendo que em sua maior parte, estas crianças residem no município de Viçosa-MG, tanto na zona urbana quanto rural. Além disso, temos também um atendimento às famílias oriundas de outras cidades, principalmente da microrregião viçosense.

Os dados revelam que crianças menores de 12 meses têm um maior índice de internação sobre as demais idades. As doenças ou causas de internação que mais acometem as mesmas são: pneumo- 
nia $(18,8 \%)$, bronquite $(11,2 \%)$, apendicite $(6,9 \%)$, infecção $(9,9 \%)$ e o restante se distribuem pelas mais diversas enfermidades (gripe, desidratação, alergia, quedas/acidentes domésticos, anemia etc.).

Tabela 1 - Relação entre crianças atendidas e reincidência de internação no Hospital São Sebastião, Viçosa/MG

\begin{tabular}{|l|c|c|}
\hline Ano & $\begin{array}{c}\mathbf{N}^{\circ} \text { de crianças atendidas } \\
\text { (março a dezembro) }\end{array}$ & $\begin{array}{c}\text { Índice de reincidência de } \\
\text { internação }\end{array}$ \\
\hline $\mathbf{2 0 1 0}$ & 375 & $32,00 \%$ \\
\hline $\mathbf{2 0 1 0}$ & 312 & $16,03 \%$ \\
\hline $\mathbf{2 0 1 2}$ & 302 & $17,02 \%$ \\
\hline
\end{tabular}

Fonte: Dados do projeto, 2012.

No que refere ao período de internação e permanência das crianças no hospital, podemos inferir que contribuímos para uma melhor aceitação do tratamento, pois as falas das mães e acompanhantes retratam uma mudança positiva no comportamento dos pequenos que foram atendidos pela equipe do projeto, confirmando a importância do brincar para a recuperação da criança. As atividades contribuíram para o desenvolvimento integral destas crianças, proporcionando condições favoráveis para que elas possam conviver bem com diferentes sentimentos gerados no ambiente hospitalar. No entanto, os dados referentes ao período de duração da internação não servem como parâmetro para avaliar se são as intervenções do projeto que colaboram na diminuição do tempo de internação da criança, pois há outras variáveis próprias da doença/enfermidade e ou da instituição que influenciam este fator.

Outros dados inferidos são os da família da criança hospitalizada, dentre eles a escolaridade. Em sua maioria, os familiares ou acompanhantes são alfabetizados, porém com "pouco estudo", ou seja, têm o ensino fundamental incompleto. Em minoria, há índices de escolaridade mais avançadas como o ensino superior. Estes dados também refletem sobre a renda dos mesmos, cujas famílias com maior grau de escolaridade têm renda, na maioria das vezes, superior àquelas que possuem menor grau de instrução.

A brinquedoteca, por se configurar como um espaço potencial de vivências, elaborações, trocas e contatos, acaba por apresentar-se como meio de superação de preconceitos, de escoamento de angústias e de ansiedades, de comunicação, tranquilização e também como uma forma de reatar laços. Durante a brincadeira, pais e filhos 
não são só cuidadores e cuidados, respectivamente, mas criam uma relação igualitária, livrando da perspectiva da doença, e principalmente, revelando um aspecto saudável da criança e estabelecendo relações de saúde. Os pais ficam nitidamente satisfeitos ao perceberem que o filho está resgatando uma atividade de sua rotina.

Usamos como referência em relação à aceitação de nosso trabalho, o reconhecimento da equipe de enfermagem, acompanhantes e crianças que já conhecem a atividade na rotina hospitalar, e que reclamam quando, por algum motivo (limitações da criança causada pelo seu estado clínico, catalogação de brinquedos e livros ou realizações de reuniões com a equipe envolvida no projeto), as atividades na brinquedoteca deixam de acontecer. Através das atividades desenvolvidas na brinquedoteca, podemos observar que a criança aceita melhor o tratamento, pois por meio da dramatização na brincadeira de médico, ao cuidar das bonecas e através da representação de histórias relacionadas à saúde, a criança expressa suas experiências vivenciadas na instituição, que se manifestam nas falas das crianças: "Olha, mãe eu vou dar uma injeção nesta boneca porque ela está dodói", "Eu vou ouvir o coração da minha boneca" ou "Eu vou trocar minha boneca, pois ela está doente".

Dentre as falas que demonstram a importância das atividades desenvolvidas na brinquedoteca, destacamos o olhar das pessoas que acompanham as crianças atendidas pelo projeto, evidenciando os benefícios deste projeto para as crianças e seus respectivos acompanhantes:

É um trabalho muito importante, pois a criança fica internada sem acesso a nada, é muito bom para a criança e também para os acompanhantes, pois ficar sem fazer nada é muito cansativo, e a criança fica muito irritada. As crianças ficam mais calmas, mas contribui mesmo é com o desenvolvimento da criança, pois aqui a criança tem acesso a diversos brinquedos, e a gente como mãe vê o interesse da criança por este ou aquele brinquedo e então muda o jeito de olhar o brincar, porque os pais e acompanhante Vê a necessidade de comprar, brinquedos para os filhos, pois muitas vezes a gente não acha importante a criança brincar (mãe de uma criança que esteve internada durante 14 dias com pneumonia).

... vocês não imaginam, estava muito apreensiva com as reações de minha filha durante o dia de hoje e a noite que virá, pois ontem foi um dia muito difícil para nós, mas após conhecermos e ficarmos um tempo aqui na brinquedoteca com vocês parece que a Natália se sentiu ali- 
viada, nem sei como explicar ela aceitou muito melhor os medicamentos e procedimentos (mãe de uma criança).

... a brinquedoteca faz bem não só para as crianças, mas para a cabeça das mães, é um lugar que deveria existir em todos os hospitais e com pessoas como vocês...(mãe de uma criança).

Ah! Este lugar é muito bom para os nossos filhos eles agora estão tão animados nem parece que estão doentes, inclusive meu filho que é diabético nem está se lembrando mais do pão que estava querendo a todo custo. É um espaço que faz muito bem para nós também. Veja! Quantas receitas culinárias nós trocamos! (mãe de uma criança diabética).

As falas evidenciam como o espaço da brinquedoteca hospitalar constitui-se em um local onde a criança pode vivenciar sua infância de forma lúdica, onde através do brincar, ela tem a possibilidade de interagir com outras crianças em situações semelhantes vivenciadas por elas no contexto hospitalar. Em cada experiência lúdica, conseguimos ver no rosto e na expressão corporal da criança internada o prazer, um sorriso, um brilho nos olhos, que em alguns momentos poderiam ser quase impossíveis acontecer no ambiente hospitalar, assim ficam perceptíveis os benefícios deste trabalho. Quanto aos acompanhantes, identificamos que, ao perceberem o bem-estar das crianças no ambiente da brinquedoteca, sentem-se confortados e mais confiantes no que diz respeito à recuperação da criança.

Em relação à humanização, um dos aspectos observados pela equipe do projeto é a dificuldade da grande maioria dos profissionais de enfermagem em fornecer, de forma clara e paciente, as respostas às indagações das crianças e suas famílias, durante o período da internação. Essas observações referem-se aos diálogos estabelecidos entre enfermeiros com as crianças e com suas famílias, às formas de abordar os familiares para solução de problemas surgidos no dia a dia, enfim, às dificuldades, em geral, dos profissionais de enfermagem em contribuir para transformar esta permanência muitas vezes dolorosa e imposta às crianças e seus familiares no hospital, em um aprendizado positivo.

Com o desenvolvimento desse projeto, percebemos que os contatos informais ocorridos entre a equipe do projeto e os profissionais do hospital e familiares das crianças têm grande impacto no que se refere à melhoria da interação da equipe de enfermagem com as crianças em tratamento, e com os acompanhantes das crianças. 
Diante destas observações, percebemos a importância do nosso trabalho junto às crianças e às famílias, sendo necessária a sinceridade ao responder as indagações das crianças de forma a esclarecer suas dúvidas sobre sua doença. É importante reconhecermos os seus temores, tentando amenizar a situação enfrentada.

\section{CONSIDERAÇÕES FINAIS}

As atividades lúdicas e criativas são primordiais na vida das crianças, independentemente da situação que as mesmas se encontram. Embora a criança tenha sido diagnosticada com uma doença grave ou não, ela não perde a sua condição de criança, tendo igual necessidade de brincar e se divertir. Mesmo sentindo mal-estar e outras limitações, o interesse por atividades lúdicas é mantido e torna-se motivo de superação de dificuldades. Neste contexto, a promoção de atividades lúdicas no ambiente hospitalar apresenta-se como uma possibilidade de atenção integral à criança e seus anseios, possibilitando que as vivências lúdicas ocupem parte de seu tempo neste espaço denominado brinquedoteca, onde a criança apropria-se de elementos próprios da infância, e tem atendido seu direito à necessidade de brincar, já reconhecidos por lei, como consta no Estatuto do Conselho Nacional dos Direitos da Criança e do Adolescente, de 1995. De forma lúdica e divertida, as crianças, mesmo enfermas, podem perceber isso de forma menos sofrível.

Como já ressaltado, o brincar é essencial ao desenvolvimento da criança e deve ser proporcionado em qualquer contexto e momento do seu desenvolvimento. Diante da experiência vivenciada neste projeto, fica evidenciado que os benefícios do brincar estendem-se também aos pais, o que fortalece a relação destes com as crianças. Sendo o brincar um meio de estabelecimento e fortalecimento de vínculos, sua promoção deve ser priorizada, principalmente, em ambiente onde o adoecimento fragiliza a relação entre a criança e seus pais e da criança com ela mesma.

Com o expressivo aumento da demanda da população no que se refere ao atendimento à saúde, sobretudo de crianças atendidas pelo SUS, e ao pleno funcionamento da brinquedoteca para atender as crianças internadas no setor de pediatria, ficam perceptíveis os benefícios deste trabalho, à medida que são proporcionadas atividades lúdicas oferecidas à população atendida, em particular, às crianças e famílias de Viçosa e região. A alegria estampada na expressão das crianças que, mesmo doentes, são capazes de sorrir, cantar, dançar, sonhar, experimentar, criar e inventar, é o resultado mais gratificante e importante para quem está envolvido em um projeto como este. 
Podemos afirmar que a relevância desse trabalho está respaldada no direito social garantido pela Constituição Federal, Estatuto da Criança e do Adolescente (direito à saúde, proteção e recuperação) e pela lei $n^{0} 11.104$, aprovada em 21 de março de 2005, que obriga os hospitais que possuem unidades pediátricas a instalar brinquedotecas.

Para qualquer pessoa que pretenda montar uma brinquedoteca, seja ela hospitalar ou não, é necessário que esteja consciente da importância do lúdico no desenvolvimento infantil e da necessidade da participação do adulto nas atividades lúdicas. De acordo com isso,

A existência de um espaço bem montado, com muitos recursos lúdicos disponíveis, não é suficiente para garantir à criança a potencialização máxima da brincadeira, nem para assegurar a orientação familiar a respeito desta. É preciso que existam profissionais com boa formação prática e teórica, com conhecimentos de técnicas de animação lúdica, de jogos, brinquedos, brincadeiras e, sobretudo, com suficiente clareza de seu papel junto à criança, no contexto de sua brinquedoteca (ANDRADE, 1992, p.85).

\section{REFERÊNCIAS BIBLIOGRÁFICAS}

ANDRADE, C.; JUNQUEIRA, M.R. A equipe na brinquedoteca. In: FRIEDMANN, A. et al. O direito de brincar: a brinquedoteca. São Paulo: Scritta Editorial: ABRINQ, 1992. p.83-94.

ARMOND, L.C. et al. Crescimento e Desenvolvimento Infantil. In: CARVALHO, A. et al. (Orgs.). Saúde da Criança. Belo Horizonte: Editora UFMG; Proex, 2002. Cap. 2, p.18-32.

BRASIL. Estatuto da criança e do adolescente (1990). Estatuto da criança e do adolescente: Lei n. 8.069, de 13 de julho de 1990, Lei n. 8.242, de 12 de outubro de 1991. 3.ed. Brasília: Câmara dos Deputados, Coordenação de Publicações, 2001.

BROUGERE, G. Brinquedo e cultura. São Paulo: Cortez, 1997.

CECCIM, R.B.; CARVALHO, P.R.A. (Org.). Criança hospitalizada: atenção integral como escuta à vida. Porto Alegre: Editora da Universidade Federal do Rio Grande do Sul / UFRGS, 1997.

CUNHA, N.H.S. Brinquedoteca: definição, histórico no Brasil e no mundo. In: FRIEDMANN, A. et al. O direito de brincar: a brinquedoteca. São Paulo: Scritta Editorial: ABRINQ, 1992. p.35-48. 
CUNHA, N.H.S.; NASCIMENTO, S.K. Brincando: aprendendo e desenvolvendo o pensamento matemático. Petrópolis, RJ: Vozes, 2005.

CAMON, V.A.A. (org.). A Psicologia no Hospital. São Paulo: Traço,1987.

DESSEN, C. J. A ciência do desenvolvimento humano: tendências atuais e perspectivas futuras. Porto Alegre: Artmed, 2005, p.172 a 177.

GUIMARÃES, D.A.; MOL, T.L.S. Casa de caridade de Viçosa - Hospital São Sebastião: Brincar na recuperação de crianças hospitalizadas. Viçosa: UFV, 2005. p.29.

KISHIMOTO, T.M. Diferentes tipos de brinquedotecas. In: FRIEDMANN, A. et al. O direito de brincar: a brinquedoteca. São Paulo: Scritta Editorial: ABRINQ, 1992. p.51-59.

MAIA, C.I.B. et al. Brinquedoteca hospitalar S.O. In: SANTOS, S.M. (Org.). Brinquedoteca: A criança, o adulto e o lúdico. Petrópolis, RJ: Vozes, 2000. p.114128.

MILLER, K. Educação infantil: como lidar com situações difíceis. Tradução Roberto Cataldo Costa. Porto Alegre: Artmed, 2008.

MITRE, R.M, Gomes, R. A promoção do brincar no contexto da hospitalização infantil como ação de saúde. 2003. In: http://www.scielo.br/pdf/\%0D/rbsmi/v7n1/ a12v07n1.pdf. Acesso em 17032012.

NEVES, N.V.G. et al. Brinquedoteca Hospitalar: Uma Estratégia de Humanização às Famílias e Crianças Atendidas no Hospital São Sebastião em Viçosa-MG. Projeto de Extensão. Viçosa, MG, 2007.

PAULA, E.T.; FOLTRAN, E.P. Brinquedoteca Hospitalar: Direito das Crianças e Adolescentes Hospitalizados. Rev.Uepg, Ed.03, 2008.

SANTA ROSA, N.S. Brinquedos e brincadeiras. São Paulo: Moderna, 2001.

SMOLE, K.C.S. A matemática na educação infantil: a teoria das inteligências múltiplas na prática escolar. Porto Alegre: Artmed, 2003.

VYGOTSKI, L.S. et al. Linguagem, desenvolvimento e aprendizagem. São Paulo: Edusp/Icone, 1988. 